\title{
Research on Traceability Application of Electronic Product Information Based on Blockchain
}

\author{
Tianyu Mao \\ College of Transport \& Communications \\ Shanghai Maritime University \\ Shanghai, China 201306
}

\author{
$\mathrm{Xu}$ Yang \\ College of Transport \& Communications \\ Shanghai Maritime University \\ Shanghai, China 201306
}

\begin{abstract}
With the development of the economy, electronic and electrical products are rapidly updating. People are increasingly demanding the upgrading of electronic products. The quality of electronic products is also receiving more and more attention. People need a reliable information system to ensure the quality of electronic products. At present, the information system of electronic products has the problems of difficulty in collecting information, non-uniform standards, and centralized structure. In view of this, this paper mainly analyzes the characteristics of blockchain applied to the traceability of electronic product information, and finds the distributed storage structure of blockchain technology to ensure the authenticity and integrity of information in electronic products from design to production to recycling. The decentralized platform and consensus mechanism of blockchain technology can effectively reduce the risk of malicious tampering of electronic products during information collection and circulation.
\end{abstract}

Keywords-blockchain; traceability of electronic product information; supply chain; consensus mechanism; distributed ledger

\section{INTRODUCTION}

\section{A. Overview of Blockchain Technology}

Since the new century, China's economy has entered a new normal. In this round of reform, information technology is the most concentrated research and development investment, the most active innovation, the most widely used, the most radiation leading role in the field, and it is the leading force leading the new round of change. Among them, the recent emergence of blockchain technology will be more efficient, fast and fair to promote the exchange of value and information, which will have an important impact on future technological innovation and industrial change [1].

In recent years, scholars have carried on the related research on the application of block chain technology in the logistics, and obtained abundant research results. Wang Lingfeng [2] and others analyzed the application of blockchain technology in aviation logistics, in which the trial operation of Dnata Shipping Company was carried out on a jointly developed logistics platform, and the block chain was used for supply chain transaction. DHL and Accenture jointly released a trend report on the application of blockchain technology to logistics, which points out that blockchain technology is fully capable of changing the entire logistics industry. Zhang Xiaohua [3] analyzes the blockchain technology and its application in the field of logistics, and points out that there are some problems in the technical level of block chain in the field of logistics, such as data confidentiality.

\section{B. Blockchain Characteristics}

Blockchain technology was first proposed by a scholar called Nakamoto [4] in Bitcoin: a Point-to-Point Electronic Cash system. The Chinese White Paper on Block chain Technology and Industrial Development prepared by China Block-chain Technology and Industrial Development Forum [5] defines it as a new application mode of distributed data storage, point-to-point transmission, consensus mechanism, encryption algorithm and other computer technologies. In a narrow sense, block chain is a kind of data information stored in a specific area in the form of chain based on the time order, and a specific password is used to ensure that the data information cannot be tampered with and forged to decentralize the shared account book. It has the characteristics of decentralization, timing data, collective maintenance, programmability, security and credibility [6].

\section{Research Background in Electronic Product Information Field}

In the face of the increasingly updated electronic products, whether from the performance of electronic products or from the appearance of packaging, consumers are increasingly demanding. Under the condition of continuous expulsion, the abandonment of electronic products has also become a very serious problem. According to the white paper on recycling and disposal of waste electronic products in 2015, China has entered the peak period of household appliance scrapping at present, and the handling capacity of discarded electronic products in China in 2015 is about 75 million units. Processing volume increased by 6.84 from 2014, and has continued to rise in the last three years. According to the survey, only 1/4 of the cases were recovered by formal enterprises. He is treated as ordinary waste or recycled by small vendors [7]. Therefore, there is no systematic process and standard for recycling and reuse of discarded electronic products, which is not only a waste of existing resources, but also an environmental problem. 
The production of electronic products is a complex process, from product design and development, raw materials supply, production, sales, consumption to recovery, reuse and so on. Because the span of this series of links management is large, every link in the supply chain appears information data break, asymmetry, cannot be traced back and so on, which leads many enterprises or small vendors to take advantage of these information loopholes and make profits from them. Therefore, it is necessary to make a series of traceability research on the information of electronic products from production to sale to recycling, so as to protect the reuse of resources and the rights of consumers, and achieve the effect of green environmental protection.

In summary, through the analysis of the current situation of the problems in the field of electronic product information, this paper puts forward the application scheme of block chain based on traceability system of electronic product information logistics, which is of great significance to the application of block chain in the field of electronic product information.

\section{ANALYSIS OF CURRENT SITUATION IN ELECTRONIC PRODUCT INFORMATION FIELD}

Electronic product information traceability is a very complicated process, from the electronic product design research and development, the material acquisition, the production, the processing, the transportation, the sale, the recovery, the manufacture each link all needs the strict supervision and management. However, due to the opacity of these processes, consumers cannot supervise and manage the whole process of supply chain of electronic products, and can only judge the quality of products by the only information. The emergence of quality problems of electronic products is essentially the opacity of information. We analyze the current situation of electronic products from the lack of traceability of information, and find the following problems:

\section{A. Production of Raw Materials}

The manufacturing process of electronic products is opaque, and many manufacturers take advantage of their opaque characteristics to cut corners from raw materials in order to reduce costs for higher self-interest. However, consumers cannot distinguish the integrity of the product or whether the material meets the safety standards when purchasing the product. In order to prevent this kind of phenomenon, the sharing of information in the production process is essential.

\section{B. Imperfection of Transportation Process Information}

With the rapid development of logistics transportation, many people will choose online shopping, including electronic products, so logistics transportation occupies a very important position in the whole process. However, electronic products are precision instruments. Improper placement during transportation may damage electronic products, thus reducing the service life of electronic products. Improving the transportation information of electronic products is an effective management measure to reduce the damage of electronic products and ensure the consumer rights and interests of buyers.

\section{Improper Recovery and Disposal of Discarded Electronic Products}

Our country enters the information age, the electronic product renewal speed is fast. A large proportion of consumers will choose to buy a new generation of electronics, and they will phase out previous electronics, even though many of them are in good use. But according to the survey, many parts of the electronic product recycling channels are irregular. Some electronic products are recycled by individual recycling operators, so the final destination of this part of the recycled electronics is opaque. There are also electronics that are left idle directly, resulting in massive waste of resources.

\section{Poor Effect of Recycling and Reuse of Electronic Products}

Recycled electronic products flow into the market after reprocessing, and some vendors mix them into new electronic products, cheating consumers.

\section{APPLICABILITY ANALYSIS OF BLOCKCHAIN BASED ON TRACEABILITY SYSTEM OF ELECTRONIC PRODUCT INFORMATION LOGISTICS}

\section{A. Distributed Account Book to Realize Information Sharing and Improve System Efficiency}

Blockchain is a "distributed account book", that is, each participant in the block chain can record and share information on the supply chain. The information can be made public by recording the information on the block chain. The members of this chain can grasp the latest information resources in real time and take corresponding measures. Realize the visualization of information and improve the efficiency of the whole system.

The block chain is applied to the entire production process of the electronic product, and each participant in the supply chain can record all the information, so that each participating member can query the information through a specific client. In this way, no matter what part of the production process, problems can be quickly found, and the corresponding responsible person can be found, consumers can also claim compensation for this.

\section{B. Collective Maintenance, Multi-subject Participation in Monitoring, Effective Prevention of Trading Fraud and Other Issues}

General trading activities are unilateral transactions, there is no authoritative supervision and management mechanism, so once the transaction problems, it cannot be held accountable. However, in the block chain mechanism, all the agents in the supply chain can record the information in this mechanism, and all the information is open and transparent to the members of the supply chain, so the members can monitor each other. So this feature of block chain can make 
up for the defects of electronic product production and trading process which cannot be effectively supervised and managed.

\section{The Reliability of Security, Ensuring the Authenticity of Recorded Information Is Beneficial to the Traceability of Products}

Block chain is a kind of consensus mechanism, and the information on the chain is encrypted by asymmetric cryptography, so this feature ensures that the content on the block chain cannot be tampered with or forged. Because of the distributed structure, all the participants in the supply chain have all the information in the chain, which further ensures the true reliability of the information, and is also conducive to the traceability of the product information.

\section{APPLICATION SCHEME OF BLOCKCHAIN BASED ON TRACEABILITY SYSTEM OF ELECTRONIC PRODUCT INFORMATION LOGISTICS}

\section{A. Design Idea}

Blockchain has the characteristics of decentralization, timing data, collective maintenance, programmable and secure. Based on these characteristics, we can record the product information from research and development stage to recycling and remanufacturing stage in the supply chain, so that we can form a time-stamped, irrevocable, secure and reliable distributed account book. Each member in this supply chain holds a private key and can query the information of the product through the network, which can act as supervision and management, and realize the idea of electronic product information traceability.

\section{B. Contrivance}

Electronic product from production to sales to recycling is a complex process, so in order to trace the information of electronic products, it is necessary to register the information in every link of electronic products. The entire process of tracing electronic product information is shown in "Fig. 1":
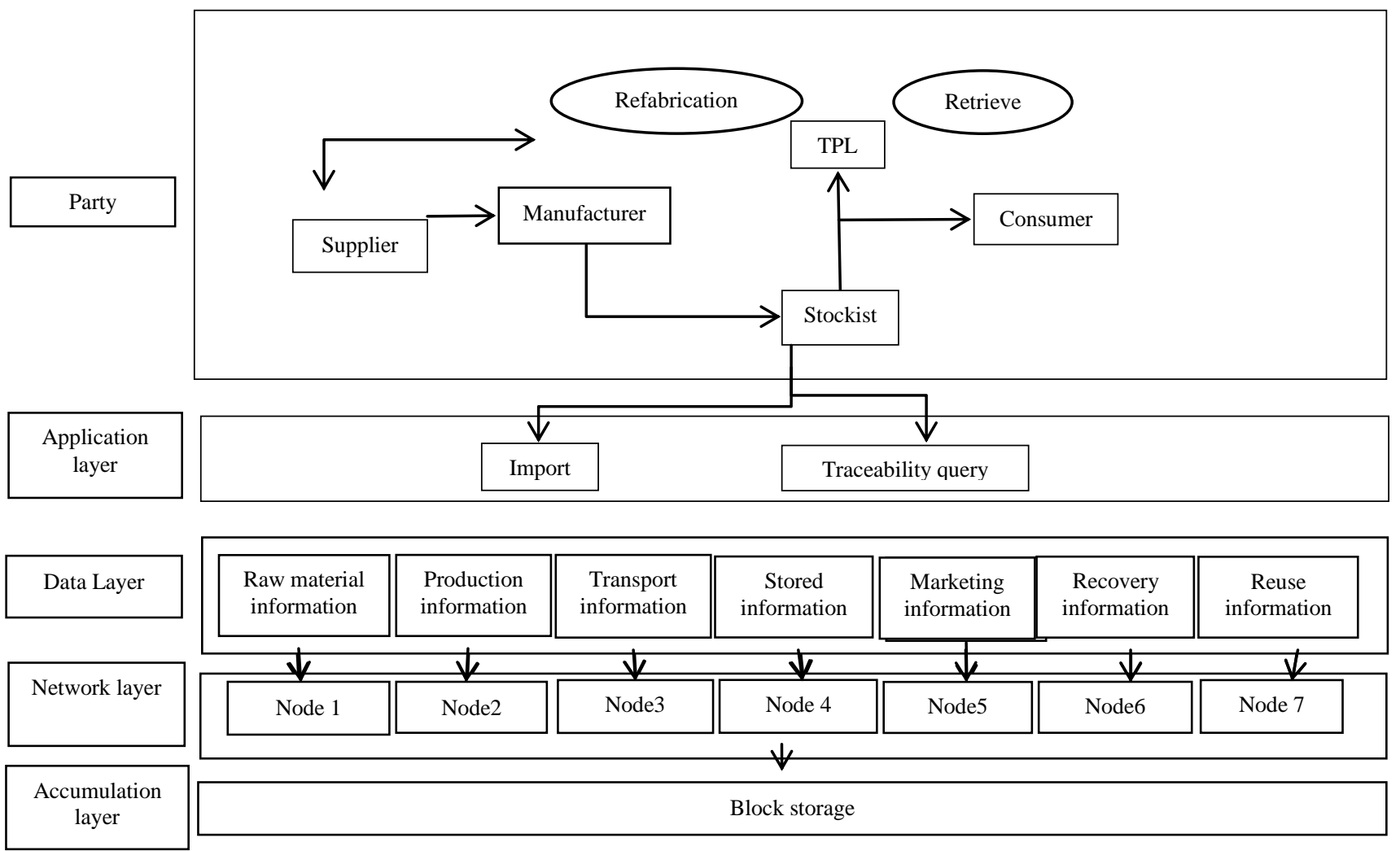

Fig. 1. Construction of traceability system of electronic product information

In the whole supply chain, the information from the beginning of the design to the final recovery and reuse is input into the system, and the block chain technology is used for distributed storage. Through this approach, everyone in the supply chain can view all the processes of electronic products through a specific query port. The following is the process of the electronics supply chain, "Fig.2": 


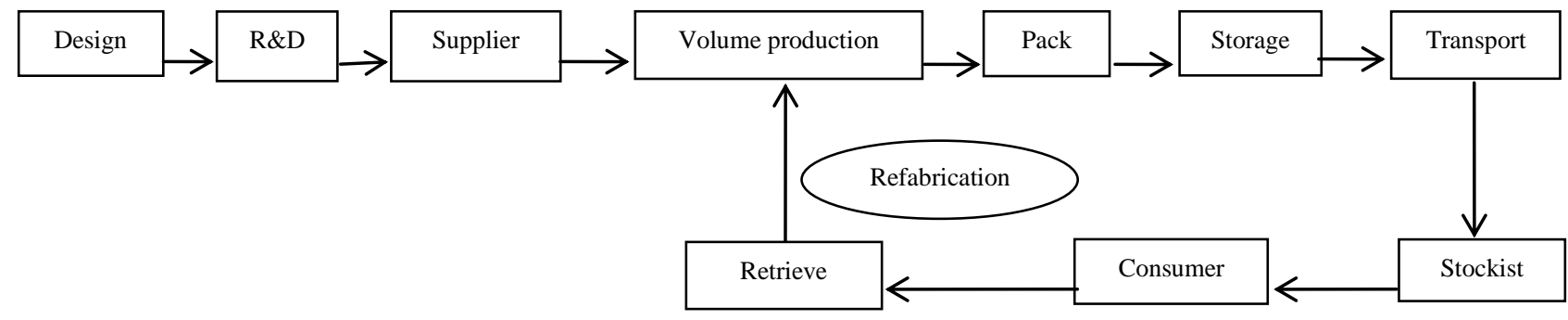

Fig. 2. Electronic products supply chain process.

1) Design and development process: The electronic product design research stage is a very important stage, where the design researchers will include the accessories used in electronic product design, including the type, style, usage model, etc., and the expected service life of the product. Product appearance packaging, product authorization and other information are recorded in the block chain. In this way, consumers can use the secret key to check whether the electronic products they buy are genuine, whether they meet the design requirements and so on.

2) Production phase: The supplier will input the material number, batch, safety grade and other basic information provided by the supplier into the system. The manufacturer will enter the production stage after receiving the raw materials, and in the production process, the manufacturer will produce the product in time of production. Production environment, production batch, serial number, production personnel information and product quality will be checked before packaging into the system and stored in the block.

3) Storage transportation stage: After the electronic product production is completed, the storage and transportation phase is required before it is supplied to the retailer. It is necessary to record the temperature, humidity and other environmental factors of the stored warehouse into the system. In order to prevent the damage caused by the storage process caused by the accumulation and extrusion of electronic products, we should record the information of the storage location of all electronic products. In the process of transportation, the third party logistics records in the system the information of the electronic products before receiving the entrustment of the manufacturer, including the packaging material, the volume and weight of the electronic products, the time of leaving the warehouse, and so on. When delivered to a customer or retailer, record the customer or retailer's and the integrity of electronic products and other information.

4) Sales phase: In the sales segment, retailers record sales in the system, including the date of sale of electronic products, online or offline purchase, purchase of customer information. Before purchasing a product, the customer can query the product through the special secret key held by the block chain technology distributed storage structure, including the raw materials of the product, the activities that take place during the transportation process, Store a series of information to determine whether the electronics you are buying are up to the mark. After the customer purchases, the information such as the problems in the process of use can be recorded in the system, so as to inquire about the use of electronic products in the recycling stage.

5) Recovery stage: There are three kinds of recycling modes in our country at present: one is the recycling of selfemployed households who run down the street, the other is the "old for new" recycling mode, which is mainly based on retailers and manufacturers. Third, the combination of individual recovery and new multi-channel recovery [10]. So in the recycling phase, the recycler needs to record the status of the electronic product that needs to be recycled in the system, including the recycling channel, the information of the recycler, the information of the customer, the time of recycling, the length of time the electronic product is in use. Information such as extent of damage is recorded in the system for customers to inquire about the recovery of recycled products.

6) Reuse stage: Recyclers uniformly recycle recycled electronics to designated manufacturers for remanufacturing. The manufacturer records in the system the information of the recycled product, the reusing of the dismantled parts, the expected service life, the flow direction of the remanufactured product, and so on. In this way, the customer who buys the reproducing product can judge the performance of the product by checking the performance of the purchased product by using the special key. This can also be done from the source of some bad businesses to substandard practices, to protect the legitimate interests of customers.

To sum up, from the product development and design, manufacturers, suppliers, vendors, consumers, recyclers are connected to the same block chain consensus mechanism, forming a shared distributed accounting system. By recording the information of the entire production cycle of the product in this system, the information flow, logistics, and so on are not tampered with, effectively reducing losses, eliminating counterfeit products, defective goods, and protecting the interests of consumers. Also provide manufacturers with product usage, better market observation, in order to make adjustments to the product.

\section{CONCLUSION}

This paper mainly studies the application of electronic products in the traceability of block chain information. In 
view of the current application of block chain in supply chain, the feasibility of using block chain in traceability of electronic product information is put forward. It is found that the block chain has a good prospect in the traceability of electronic product information. But at present, this kind of research only stays in the theory research stage, does not have the mature technical support.

Previous studies have mainly focused on the theory of block chain, and the application of block chain in electronic products is basically absent. In this paper, the application of block chain in traceability of electronic product information is first put forward. The next research work is to give full play to the application of block chain in this field and achieve the effect of green logistics by considering the development of data encryption technology.

\section{REFERENCES}

[1] Li Hongxing, Wang Zhuang, Zheng Haowen. Discussion on the operation mode of express delivery in the same city of China [J]. Logistics Technology, 2015 (24).

[2] Wang Lingfeng, Chen Yuping. Application of block chain technology in aviation logistics [J]. Air Transport Business, 2018 (04): 53-54.

[3] Zhang Xiaohua. Analysis of block chain technology and its application in logistics [J]. Science, Technology and Economics, 2017: 18: 19-20.

[4] Nakamoto S. Bitcoin: Point-to-peer electronic cash system [online] that provides: https://bitcoin.org/bitcoin.pdf, 2009.

[5] Zhou Ping. White paper on block chain technology and industrial development in China [M]. Beijing: Ministry of Industry and Information, 2016.

[6] Yuan Yong, Wang Leap. Current situation and prospect of block chain technology [J]. Journal of Automation, 2016N 42 (04): 481-494.

[7] Van Kelon. Where is electronic garbage going? [N]. Anhui Daily, 2016-10-20 (005).

[8] Zhou Ya-wen, Huang Jizhong, Xu Hongsheng. Zhou Quan method. Recycling mode and disposal technology of waste electrical and electronic products in China [J]. Recycling Resources and Recycling economy, 201811 (06): 16-20. 